\title{
PARACOCCIDIOIDOMICOSE EVIDENCIANDO COMPROMETIMENTO MEDULAR TRATADA COM SUCESSO POR FLUCONAZOL
}

\author{
LEANDRO PAJUABA DE MOURA *, CESAR NORONHA RAFFIN**, GILDA M.B. DEL NEGRO***, \\ MARCELO SIMÃO FERREIRA *** *
}

\begin{abstract}
RESUMO - O envolvimento do sistema nervoso central na paracoccidioidomicose tem sido raramente descrito na literatura e sua frequência varia de $9,99 \%$ a $27,27 \%$, manifestando-se basicamente sob duas formas clínicas: meníngea e pseudotumoral (abscessos, granulomas, nódulos ou cistos). OParacoccidioides brasiliensis incide principalmente nos hemisférios cerebrais, podendo acometer ainda cerebelo, ponte, bulbo, meninges cerebrais e raquidianas, sendo excepcional o comprometimento do parênquima medular. Os autores apresentam o caso de um paciente com paracoccidioidomicose com evidências clínicas de comprometimento medular, comprovada por exames complementares indiretos pouco invasivos. Destacam a resposta terapêutica inédita a novo agente antifúngico bistriazólico, o fluconazol, pela primeira vez utilizado nesta forma de apresentação clínica da doença. Salientam a rariedade do comprometimento medular, o diagnóstico através de propedêutica nāo cirúrgica e a excelente resposta a este novo tratamento.
\end{abstract}

PALAVRAS-CHAVE: paracoccidioidomicose, medula espinhal, fluconazol.

\section{Paracoccidioidomycosis evidencing spinal cord involvement successfully treated by fluconazole}

SUMMARY - The involvement of central nervous system in paracoccidiodomycosis has rarely been described, with an incidence rate varying from $9.99 \%$ to $27.27 \%$. There are two basic forms of clinical presentation: meningeal and tumor-like (abscesses, granulomas, nodules, and cysts). The Paracoccidioides brasiliensis is preferentially described in cerebral hemispheres, cerebellum, medulla oblonga and meninges, and exceptionally in the spinal cord. The authors present a case of paracoccidioidomycosis which diagnosis was achieved by microscopic examination of material from oral lesions and specific serology. The patient presented clinical signs of spinal cord involvement confirmed by lesions found in magnetic resonance imaging. They emphasize the inedit therapeutic response to a new antifugal agent (fluconazole) used for the first time in this kind of clinical manifestation, and the excellent prognosis when diagnosis is promptly made.

KEY-WORDS: paracoccidioidomycosis, spinal cord, fluconazole.

A paracoccidioidomicose é infecçāo sistêmica causada por fungo dimórfico, o Paracoccidioides brasiliensis (P. brasiliensis). Sua ocorrência é comum em zonas rurais da América Latina e no Brasil, onde sua prevalência é maior, a micose incide mais comumente na regiāo sudeste, em particular, nos Estados de São Paulo e Minas Gerais ${ }^{3,14}$. Adquire-se a infecção, na grande maioria das vezes, por inalaçāo do fungo presente na natureza ou, mais raramente, por implantaçāo traumática cutânea ou mucosa. A micose se traduz clinicamente pelo comprometimento primário do aparelho respiratório, observado predominantemente nas formas da moléstia em

* Neurologista, Departamento de Clínica Médica, Universidade Federal de Uberlândia (UFU); **Professor Titular de Neurologia, Departamento de Clínica Cirúrgica, UFU; ***Micologista responsável pela sorologia em Micologia, Laboratório de Investigação Médica 53 (LIM-53), Faculdade de Medicina da Universidade de São Paulo (Chefe: Prof:: Dr. Carlos da Silva Lacaz); ****Professor Titular, Departamento de Clínica Médica (Doenças Infecciosas e Parasitárias), UFU. Aceite: 8-julho-1993.

Dr. Leandro Pajuaba de Moura - Rua Johen Carneiro 825, Bairro Lídice - 38400-031 Uberlândia MG - Brasil. 
adultos ${ }^{14}$, por lesōes cutâneas e mucosas e pelo enfartamento ganglionar localizado ou generalizado. $O$ acometimento do sistema nervoso central (SNC), cuja frequência varia de $9,99 \%^{25}$ a $27,27 \%^{2}$, pode exteriorizar-se basicamente sob duas formas clínicas: meníngea e pseudotumoral ${ }^{17,21}$, podendo esta apresentar-se como abscessos, granulomas, nódulos ou cistos ${ }^{11}$. O envolvimento do SNC, sempre secundário a foco localizado em geral na mucosa bucofaríngea ou nos pulmōes ${ }^{21}$, é menos raro do que se acredita ${ }^{18}$, devido ao fato de frequentemente nāo haver: a) apresentaçāo clínica (formas neurológicas assintomáticas); b) exame neurológico especializado e investigaçăo rotineira do SNC por tomografia axial computadorizada ou ressonância magnética (RMI); c) estudo sistematizado do SNC em necrópsias². O P. brasiliensis incide principalmente nos hemisférios cerebrais (granulomas solitários ou múltiplos) ${ }^{2426}$, podendo acometer ainda cerebelo, ponte, bulbo, meninges cerebrais e raquidianas, sendo excepcionalmente descrito no parênquima de medula espinhal $4,9,13,21,22,24$.

Na maiorià, os casos de comprometimento medular relatados em literatura foram achados cirúrgicos ocasionais ou de necrópsia, fato justificável apenas quando esta localizaçāo é isolada ${ }^{24}$, sendo habitual a presença do fungo em outros locais do organismo. Este fato auxilia o diagnóstico etiológico da micose nesta rara localizaçăo ${ }^{2,21}$. Registramos um caso com evidências de localizaçāo medular.

\section{RELATO DE CASO}

JBC, masculino, 57 anos, faiodérmico, casado, natural de Coromandel (MG)e residente em zona rural do município de São Félix do Araguaia (MT), foi internado no Serviço de Neurologia do Hospital das Clínicas da Universidade Federal de Uberlândia em 5-março-1991 com história de 20 dias antes ter iniciado a apresentar parestesias em membro inferior (MI) direito (D) evoluindo para o MI esquerdo (E) seguidas por paraparesia progressiva, assimétrica e ascedente; cinco dias após, apresentou quadro sucessivo de retençāo urinária, obstipaçāo intestinal e perda total da deambulação. Relatava emagrecimento de $12 \mathrm{~kg}$ no período de um mês. Em antecedentes patológicos referia "doença pulmonar" há oito anos, tratada em outro serviço e "abscesso" em regiāo parotídea E há um ano. Relatava ainda lesōes nos lábios e orofaringe há um mês. $O$ exame físico geral revelou: paciente em regular estado geral, extremamente emagrecido, observando-se na comissura labial D lesāo ulcerada finamente granulosa, friável, dolorosa (Figura 1) e ulceração de fundo granuloso fino, com pontilhado hemorrágico entremeada a minúsculas máculas amareladas no palato mole. $O$ exame neurológico mostrou paraplegia espástica grau zeró e hiperreflexia profunda nos MMII, sinal de Babinski bilateral, reflexos cutâneos-abdominais abolidos, anartrestesia, apalestesia e hipoestesia tátil a nível de T10. Estabelecida a impressão diagnóstica de mielite transversa e paracoccidioidomicose, esta confirmada pelo isolamento do fungo das lesōes orais (Figura 2). Exames complementares - Líquido

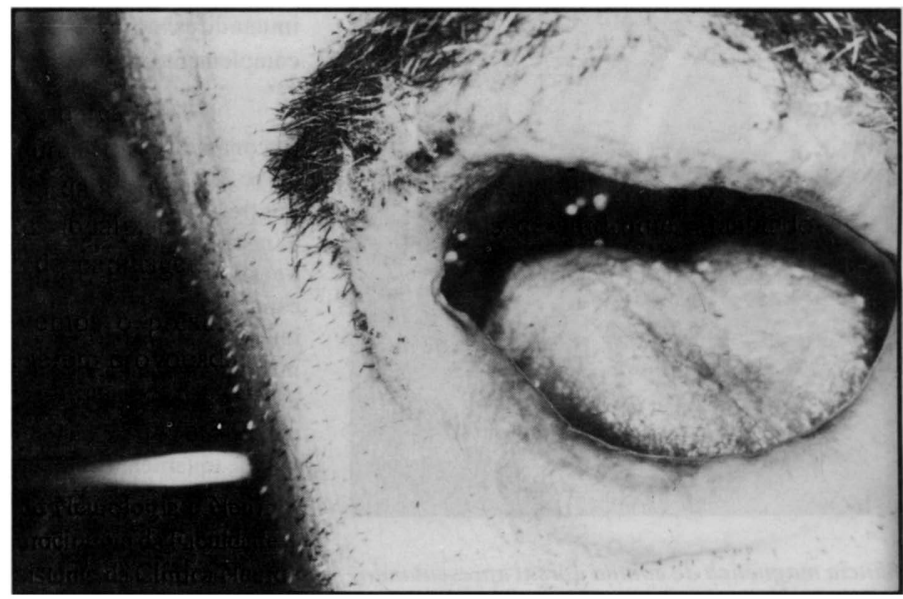

Figura 1. Caso JBC. Lesões ulceradas finamente granulosas, friáveis, com pontilhado hemorrágico, acometendo comissura labial direita. 


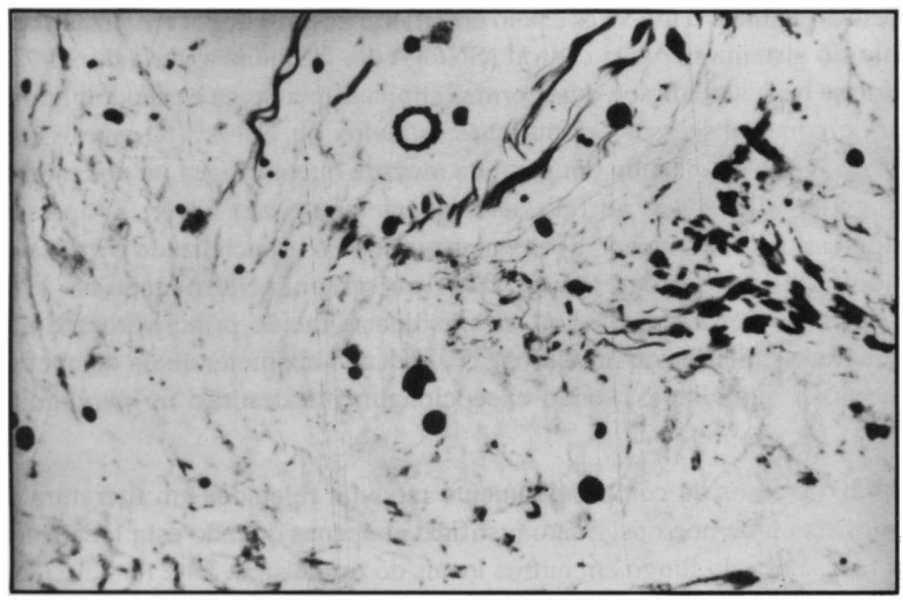

Figura 2. Caso JBC. Histopatologia da lesão descrita na Figura 1, mostrando o Paracoccidioides brasiliensis, corado pela prata (método de Gomori-Grocott, 500X).

cefalorraqueano (LCR): incolor, límpido; glicose $58 \mathrm{mg} / \mathrm{dL}$, proteínas $45 \mathrm{mg} / \mathrm{dL}$, reaçōes de Nonne e Pandy negativas; células $/ \mathrm{mm}^{3} \mathbf{0}$, hemácias $/ \mathrm{mm}^{3} 0$; pesquisa direta de fungos e cultura para fungos, negativas; pesquisa de células neoplásicas, negativa. Soro: VDRL, FTA-Abs, anti-HIV, nāo reativos; eletroforese de proteínas ( $\mathrm{g} / \mathrm{dL}$ ): proteínas totais 6,8, albumina 2,94, alfa-1 0,35, alfa-2 1,87, beta 0,98, gama 1,53; mucoproteínas 6,7 mg/dL. Escarro: pesquisa de BAAR negativa. Eletrocardiograma: ritmo sinusal, perturbado por raras extra-sístoles ventriculares isoladas, alteraçōes primárias da repolarizaçāo ventricular em parede ântero-lateral, QTc prolongado (retardo da sístole elétrica). Ultrassonografia abdominal normal. Radiogra fia de tórax: discretas áreas de condensaçāo heterogênea em regiōes peri-hilares e no lobo superior do pulmäo D. Mielogra fia: normal. RMI da coluna dorsal (Figura 3): medula espinhal apresentando imagem em seu interior de hipersinal em T2 que se prolonga aos segmentos de D3 a D11; estas alteraçōes da intensidade de sinal da medula sāo compativeis com lesāo isquêmica ou inflamatória. Histopatológico (lesōes orais): reaçäo inflamatória intensa no tecido conjuntivo, tipo crônica-específica, rica em células gigantes tipo Langhans; dentro e fora das células gigantes, observa-se a presença de fungos com morfologia compatível à do $P$. brasiliensis (Figura 2). Reaçōes para P. brasiliensis - Soro: fixação de complemento pelo micrométodo, positiva;

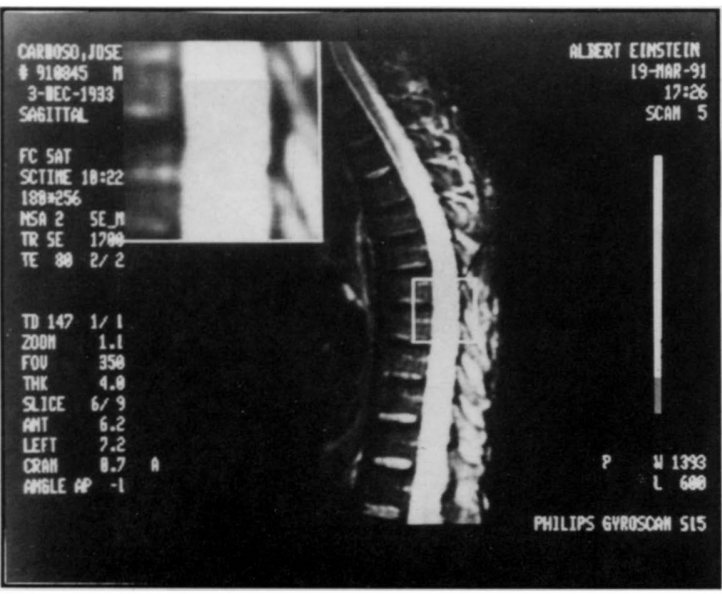

Figura 3. Ressonância magnética de coluna dorsal apresentando, no interior da medula espinhal, imagem de hipersinal em T2 que se prolonga aos segmentos de D3 a D11, compativeis com lesão isquêmica ou inflamatória. imunodifusão em gel de ágar, positiva; reaçāo de precipitaçāo, positiva; contraimunoeletroforese, positiva (1:32). LCR: imunodifusāo radial, negativa; fixação de complemento, negativa.

Evolução - Iniciado uso de fluconazol via oral na dose de $400 \mathrm{mg}\left(1^{2}\right.$ dia) e $200 \mathrm{mg} /$ dia como manutenção. Após quatro dias houve discreta melhora da parestesia em regiāo toráxica e abdominal, persistindo os sintomas motores e esfincterianos. No $14^{\circ}$ dia apresentava dores intensas nos MMII, tipo "choque", que foram minimizadas com o uso de amitriptilina. No $2^{2}$ mês houve melhora da motricidade, persistindo os sintomas esfincterianos. No $4^{\circ}$ mês de tratamento, reiniciou a deambulação com apoio e obteve controle de esfincter vesical, sendo retirada definitivamente a sonda vesical. № $\boldsymbol{T}^{\boldsymbol{T}}$ mês deambulava com dificuldade, sem apoio. No $11^{\circ}$ mês apresentava deambulação praticamente normal, persistindo hiperreflexia e sinal de Babinski, com controle irregular deesfincter anal. 


\section{COMENTÁRIOS}

A paracoccidioidomicose medular, como já citado, é extremamente rara, existindo apenas cinco casos publicados na literatura mundial, comprovados mediante cirurgia e isolamento do fungo ao exame histopatológico, sendo interessante destacar a resposta inadequada a este tipo de abordagem, mesmo quando seguida pelo tratamento anti-fúngico convencional 4,13,21-24. Vários autores relatam casos com provável comprometimento do parênquima medular sem comprovaçāo etiológica, num total de sete casos, alguns deles com recuperação após tratamento clínico ${ }^{6,7,17,26}$.

A topografia medular diagnosticada clinicamente e comprovada pela RMI de coluna dorsal (Figura 3), denota o avanço dos recursos propedêuticos nāo invasivos e demonstra que a abordagem cirúrgica nāo pode mais ser considerada procedimento diagnóstico como preconizado outrora ${ }^{24}$, estando atualmente contra-indicada por vários autores ${ }^{21}$.

É descrita, atualmente, a presença do fungo em vários territórios do SNC, sem exteriorizaçāo clínica, sendo sugerida na literatura a investigação neurorradiológica de todos os portadores de paracoccidioidomicose indiscriminadamente ${ }^{2,22}$.

Os dados fornecidos pelo exame de rotina do LCR em casos de paracoccidioidomicose do SNC, como a pleocitose com predomínio linfomononuclear, hiperproteinorraquia e hipoglicorraquia, são de baixa sensibilidade e especificidade ${ }^{16,24,26,28}$, o que é confirmado neste relato pela normalidade do exame de rotina do LCR. O resultado negativo da pesquisa do fungo no LCR, observado neste paciente, é comprovado na literatura, pela raridade do seu achado tanto à pesquisa direta ${ }^{19,26}$ quanto à cultura ${ }^{26}$ não constituindo, portanto, elemento para a exclusão diagnóstica ${ }^{10}$.

Quanto aos achados imunológicos no LCR, Lacaz e col $^{17}$ concluíram pela não especificidade destas reaçōes para o SNC, referindo ainda que sua positividade pode ocorrer no indivíduo sem lesōes fúngicas no SNC desde que a barreira hematoliquórica (BHL) esteja alterada, permitindo a passagem de anticorpos sanguíneos. Tais conclusōes devem ser atualmente questionadas, visto que hoje se consegue diagnosticar os casos neurológicos assintomáticos por métodos de neuroimagem nāo existentes na época.

Finalmente, optou-se pelo tratamento com fluconazol pelas suas propriedades antifúngicas comprovadas sobre o P. brasiliensis ${ }^{12,29,30}$ e maior especificidade contra o citocromo P-450 dos fungos com consequente menor toxicidade quando comparado ao ketoconazol ${ }^{15}$, além da facilidade de administraçāo por via oral e da elevada concentraçāo atingida no SNC $(50$ a $60 \%$ da concentração sérica no LCR de indivíduos com a BHL íntegra e cerca de 70 a $90 \%$ em pacientes com a BHL alterada) $)^{29,30}$.

Destaca-se ainda, o modo de instalaçāo da paraplegia e o tempo decorrido entre o início dos sintomas e o início do tratamento (26 dias no caso apresentado), fatores decisivos no prognóstico destes pacientes ${ }^{27}$. As fortes dores nos MMII, surgidas no início do tratamento, foram interpretadas por nós como possível reaçāo inflamatória exacerbada pela morte do fungo. Esta já havia sido anteriormente questionada por Morato-Fernandes e $\mathrm{col}^{22}$, analogamente ao que ocorreria na neurocisticercose frente ao albendazol. Contrariamente ao proposto por tais autores, o uso do corticosteróide neste paciente foi evitado pela possibilidade de disseminaçāo do fungo, que possui comportamento diverso do Cysticercus cellulosae na presença deste medicamento ${ }^{15,20}$.

\section{REFERÊNCIAS}

1. Aun RA. Blastomicose do cerebelo: forma tumoral. Arq Hosp Santa Casa S Paulo 1957, 3: 63-70.

2. Azevedo AP. Lesōes do sistema nervoso central na doença de Lutz (blastomicose brasileira). O Hospital 1949, 36: 465-487.

3. Barbosa W, Daher RR. Blastomicose sul-americana/Paracoccidioidomicose. In: Veronesi R. Doenças infecciosas e parasitárias. Ed 8. Rio: Guanabara Koogan 1991, p 634-646.

4. Braga FM, Okamura M. Blastomicose medular (apresentação de um caso cirúrgico). Seara Méd-Neurocir (São Paulo) 1973, 1: 435-441. 
5. Bucy PC, Oberhill HR. Intradural spinal granulomas. J Neurosurg 1950, 7: 1-12.

6. Canelas HM, Lima FP, Bittencourt JMT, Araújo RP, Anghinah A. Blastomicose do sistema nervoso. Arq Neuropsiquiatr 1951, 9: 203-222.

7. Cunha JCP, Magaldi C, Barros C. Localização nervosa da blastomicose sul-americana. Rev Bras Med 1955, 12:3-13.

8. De Jong R. The neurologic examination. Ed 4. New York: Harper \& Row 1979, p 338.

9. Del Negro G, Albuquerque FJM, Campos EP. Localização nervosa da blastomicose sul-americana: revisão de literatura e registro de dois casos. Rev Hosp Clínicas 1954, 9: 64-80.

10. Del Negro GMB, Garcia NM, Rodrigues EG, Cano MIN, Aguiar MSMV, Lírio VS, Lacaz CS. The sensitivity, specificity and efficiency values of some serological tests used in the diagnosis of paracoccidiodomicose. Rev Inst Med Trop Sāo Paulo 1991, 33: 227-280.

11. Del Negro G, LacazCS, Fiorillo AM. Paracoccidioidomicose-Blastomicose sul-americana. São Paulo: Sarvier 1982.

12. Dismukes WE. Azole antifugal drugs: old and new. Ann Intern Med 1988, 109: 177-179.

13. Farage M Filho, Braga MRG, Kuhn MLS. Granuloma blastomicótico na medula cervical: registro de um caso. Arq Neuropsiquiatr 1977, 35: 151-155.

14. Ferreira MS. Contribuição para o estudo clínico-laboratorial e terapêutico da forma juvenil da paracoccidioidomicose. Tese de Livre-Docência. Universidade Estadual do Rio de Janeiro. Rio: 1988.

15. Godoy JF. Evoluçāo de 20 doentes de paracoccidioidomicose tratados pela anfotericina B associada a corticóide. Folha Med 1988, 96: 59-61.

16. Guimarães RX. Clínica e Laboratório: interpretação das provas laboratoriais. Ed 3. São Paulo, 1983.

17. Lacaz CS, Assis JL, Bittencourt JMT. Micoses do sistema nervoso. Arq Neuropsiquiatr 1947, 5: 1-52.

18. Lemmi O, Pimenta AM. Granuloma paracoccidióidico cerebral: a propósito de um caso operado. Arq Neuropsiquiatr 1960, 18: 58-63.

19. Levy JA, Dillon N, Menezes JR Neto, Sampaio SAP. Meningite na blastomicose sul-americana (Resumo). Rev Paul Med 1959, 55: 519-520.

20. Londero AT, Santos JW, Silva LA, Ramos CD. Paracoccidioidomicose induzida por droga imunossupressora em paciente com lúpus eritematoso sistêmico. Arq Bras Med 1988, 62: 185-187.

21. Marchiori E, Freitas MAL, Lima RAM. Paracoccidioidocomicose medular: relato de um caso. Arq Neuropsiquiatr 1989, 47: 224-229.

22. Morato-Fernandez RN, Beraldo PSS, Masini M, Costa PHC. Paracoccidioidomicose de localizaçäo intramedular e cerebral. Arq Neuropsiquiatr 1991, 49: 192-197.

23. Osmond JD, Schweitzer G, Dunbar JM, Path MRC, Villet MB. Blastomycosis of the spine with paraplegia. S Afr Med J 1987, 45: 431-434.

24.Pedro RJ, Branchini MLM, Lucca RS, Silveira ML, Facure NO, Amato V Neto. Paracoccidioidomicose do SNC: a propósito de dois casos. Rev Inst Med Trop São Paulo 1980, 22: 269-274.

25. Pereira WC, Raphael A, Sallum J. Lesōes neurológicas na blastomicose sul-americana: estudo anátomo-patológico de 14 casos. Arq Neuropsiquiatr 1965, 23: 95-112.

26. Raphael A. Localização nervosa da blastomicose sul-americana. Arq Neuropsiquiatr 1966, 24: 69-90.

27. Ropper AH, Poskanzer DC. The prognosis of acute and subacute transverse myelopathy based on early signs and symptoms. Ann Neurol 1978, 4:51-59.

28. Spina-França A. Eletroforese das proteínas do líquido céfalorraqueano: principais resultados registrados na literatura. Arq Neuropsiquiatr 1958, 16:223-235.

29. Tavares W. Manual de antibióticos e quimioterápicos anti-infecciosos. São Paulo: Atheneu, 1990, p 620-621.

30. Tucker RM, Williams PI, Arathoon EG. Pharmacokinetics of fluconazole in cerebrospinal fluid and serum in human coccidioidal meningitis. Antimicrob Agents Chemother 1988, 32: 369-372. 